\title{
Stressors in the Working Environment of Registered Nurses
}

Krystal Ellington Canady* and Debbie Allen

College of Health Sciences, School of Nursing, Georgia College, 231 W. Hancock St., Milledgeville, GA 31061, USA

\section{Abstract}

Objective: To provide support for nurse leader interventions that decrease workplace stressors for nurses. Background: Hospital nursing is highly stressful with persistent, unremitting emotional and physical strain creating unhealthy workplaces threatening the quality and safety of patient care, and decreasing the quality of life and personal health of nurses. Nurse leaders must assess stressors and implement stress reduction strategies to promote nurse personal health.

Methods: The Health and Safety Executive (HSE) 35 item valid and reliable questionnaire was administered to Registered Nurses(RNs) in four hospitals located within Georgia.

Results: RNs (464) reported increased high work demands; new nurses and nurses approaching retirement reported the highest stress perceptions.

Conclusion: Ultimately, hospital administrators must take responsibility to create and foster a practice environment that ensures the health and safety of nurses.

\section{Introduction}

Hospital nursing is highly stressful with persistent, unremitting emotional and physical strain that can create unhealthy workplaces for nurses and threatening the quality and safety of patient care $[1,2]$. Key factors affecting nurses' overall job satisfaction include workplace culture, quality of care, safety, and environment. Important invisible characteristics include the attitude, values, and behaviors of nurses [3]. Effective teamwork is vital to the delivery of high quality patient care [3]. Kaufman and McCaughan studied teamwork culture and found that effective teamwork is a basic tool when providing good patient care, and recognized overall system malfunctions and errors were decreased in effective teamwork organizations [3]. Perry discovered a positive, beneficial, cyclical relationship between nurse career and patient satisfaction [4]. However, Registered Nurses (RNs) face more challenges than just patient needs; nurses, co-workers, administrative demands, work speed, and unachievable deadlines are major stressors [4]. Forty-nine percent of RNs report verbal abuse, condescending language, and insufficient responses of nurse colleagues most frequent of those, 50\% reported minimal occurrences every three months[5]. Acute care (operating room, emergency room, and critical care) nurses report high levels of verbal abuse from nurse colleagues compared to other units with significant lower levels of autonomy, poor supervisor and mentor support, and reduced workgroup cohesion ( $\mathrm{p}=.0001)$ [6] Evidence-based identification and plans to address the most common stressors of workplace aggression, incivility, violence, harassment, insults and vulnerability are vital. The purpose of this article is to provide the top $\mathrm{RN}$ inpatient workplace stressors and propose stress reduction strategies that allow administrators to enhance nurse satisfaction. This article addresses a synthesis of the literature, project methodology, results, conclusions of a Doctor of Nursing Practice (DNP) Clinical Project, and its implications for nursing.

\section{Literature Review}

Quality patient care is negatively associated with nurse stressors such as increased burnout, staff turnover, shift work, long work hours, continuous change, extreme emotional demands [7] and poor morale[8]. Stress reduction and health improvements are vital to quality patient care, nurse job performance and retention, and sick time reduction. The Institute of Medicine (IOM) called for nurse work environment change to meet these needs [9]. Extended work shift hours expose nurses to increased workplace stressors compared to regularly scheduled shifts [10] and an increase in accidents, injuries, and other incidents are associated with long work hours [10-15]. Nurses work 12-hour shifts to provide continuous 24-hour inpatient care creating sleep deprivation and higher stress demands. Consequently, risks for chronic illnesses such as obesity, hypertension, diabetes, and other mental or physical ailments increase [12]. The American Nurses Association (ANA) Health System Reform Agenda highlighted support for quality health care policies to be based on outcomes reflecting the Six Quality of Aims guidelines of the IOM report. By 2017 Medicare reimbursement will be affected by hospital and nurse performance that obtain positive quality patient outcomes [16].

The Centers for Medicaid and Medicaid Services (CMS) [17] examined the increases in health care costs and created the Partnership for Patients initiative that determined new reimbursement methods to improve patient quality and safety and reduces costs[16]. For the first time in US history, hospitals are financially rewarded for achieving improved patient outcomes; links between adherence to shared best practices and evidence from published outcomes data demonstrate increases in patient safety and quality of care. Read mission rates of Medicare recipients within 30 days of discharge is nearly $20 \%$ contributing to decreased patient satisfaction and rising healthcare costs [18]. A healthy nurse workforce is directly linked to improved patient outcomes[19]. A reduction in adverse patient events is attributed to the participation, philosophy, staffing of nurses, supportive managers, and mutual relationships between physicians and nurses [20]; nurse work schedules are significantly linked to patient mortality when staffing levels and hospital characteristics were controlled [13]. A significant association between nursepatient ratios, nurse turnover, and reduction in urinary and surgical site infections resulted in a $\$ 68$ million saving annually [21]. To increase quality health care, nurses need stress management support; organizations must commit to increasing nurse satisfaction[22].

"Corresponding Author: Prof. Krystal Ellington Canady, College of Health Sciences, School of Nursing, Georgia College, 231 W. Hancock St., Milledgeville, GA 31061, USA; Tel: 478-290-4638; E-mail: kme_555@yahoo.com

Citation: Canady KE, Allen D (2015) Stressors in the Working Environment of Registered Nurses. Int J Nurs Clin Pract 2: 157. doi: http://dx.doi. org/10.15344/2394-4978/2015/157

Copyright: (c) 2015 Canady et al. This is an open-access article distributed under the terms of the Creative Commons Attribution License, which permits unrestricted use, distribution, and reproduction in any medium, provided the original author and source are credited. 
Nursing shortages and long hours of work result in mental and physical complaints from nurses; complaints of mental stress, mild depression, and anxiety disorders lead to healthcare professional impairments and decreased work performance [13]. The prevalence of mental and physical complaints, and the lack of resources available, requires nurse leaders to be proactive and implement interventions that improve nurse satisfaction and therefore quality patient care. Transformational leaders recognize, appreciate, and compliment nurses on all forms of positive nursing actions and all forms of acknowledgements [23]. Patient safety, in terms of reduced adverse events and complications, increases quality patient care, nurse career satisfaction and safety, decreased job stress and is linked to transformational leaders who advocate for teamwork $[19,20]$. Transformational nurse leaders must ensure that the work environments limit stressors to allow nurses to do their job effectively. For success, nurses need recognition from superiors when making positive connections with patients to feel that they are thriving and "fall in love with their work" [4]. Therefore, research is vital to identify appropriate frequently reported nurse stressors and implement changes that decease that stress which will improve safe, patient care.

\section{Methodology}

Kurt Lewin's change theory was used as the framework of the study due to its change success using three stages: unfreezing (empowerment to relinquish old, counterproductive patterns of behavior), change (thoughts, feelings, and/or behavior changes that produces liberating or productive outcomes), and refreezing (verifying new behavior as standard practice, unyielding, and denies regression to previously flawed methods [24]. The research questions are stated and answered in the "Study Questions Results" section.

\section{Instrument}

The Health and Safety Executive (HSE) 35 self-report questionnaire was chosen due to its ability to evaluate work-related stressors. It has six subsets of stressors: demands (8); control (6); support (5); relationships (4); role (5); and change (3) using a 5 point Likert scale to measure stress $(0=$ no stress, $5=$ extreme stress $)$ with a psychometric reliability Cronbach's alpha of $0.75-0.86$ [25]. However, only the top stressors reported by nurses within the subsets are discussed in this article.

\section{Participants}

Five hospitals with varying demographics were contacted for participation; four agreed to participate and appropriate Institutional Review Boards (IRB) approvals obtained prior to any data collection. These facilities included a: 200 bed level three trauma facility,rural health organization with 125 beds, 300 bed for-profit facility, and 400 bed, level 1 trauma Magnet status hospital increasing generalizability. Seven hundred packets, labeled with a special code for each facility for easy identification, coding, and evaluation, were created and distributed containing a consent form, demographic data sheet, and survey with a target return rate of $50 \%$. Participation was voluntary at each facility and completion of the survey implied consent. After training by the researcher, each hospital assisted with recruitment efforts including presentations to nurse managers and departmentbased educators; nurse leadership supported, encouraged and enabled staff RN participation. Nurses were given three weeks to complete the survey and return his/her packed to the researcher; 464 were returned (60\%).

\section{Data Analysis}

Data were entered into the SPSS v21 program as it was received. Once entered, descriptive statistics were used to analyze the demographic and unit specific responses. Logistic regression analysis was used to evaluate the association between each of the 35 items and the various aspects of the psychosocial work environment at a $95 \%$ confidence interval. Overall nurse responses, not facility type,nor subsets of the instrument are reported at this time. A one way analysis of variance (ANOVA) was conducted to answer top stressor questionsto control for type I error, Dunnett's C was performed.

\section{Results}

Most participants were Caucasian (75\%), women (84\%), between the ages of 35-54 years (29\%), and married (64\%). Most nurses were full time employees (79\%), $46 \%$ were prepared at the baccalaureate level, and $36 \%$ had $0-5$ years of experience (Table 1).

\begin{tabular}{|c|c|c|}
\hline Demographic Data & n (\%) & Total Stress \\
\hline \multicolumn{3}{|l|}{ Gender } \\
\hline Male & $51(11)$ & 81.190 \\
\hline Female & 81.190 & 84.181 \\
\hline \multicolumn{3}{|l|}{ Age in Years } \\
\hline 18- 24 years & $66(14)$ & 83.681 \\
\hline 25-34 years & $134(29)$ & 84.470 \\
\hline $35-44$ years & $91(20)$ & 82.555 \\
\hline $45-54$ years & $92(20)$ & 83.681 \\
\hline $55-64$ years & $52(12)$ & 83.980 \\
\hline 65 years or older & $5(1)$ & 88.400 \\
\hline \multicolumn{3}{|l|}{ Marital Status } \\
\hline Married & $285(64)$ & 83.390 \\
\hline Never Married & $8619)$ & 84.164 \\
\hline Living with Other & $19(5)$ & 85.578 \\
\hline Separated & $2(.5)$ & 98.500 \\
\hline Divorced & $45(10)$ & 83.775 \\
\hline Widowed & $3(.6)$ & 89.000 \\
\hline \multicolumn{3}{|l|}{ Ethnicity } \\
\hline Black & $69(15)$ & 80.260 \\
\hline Caucasian & $349(75)$ & 84.390 \\
\hline Hispanic & $7(2)$ & 80.000 \\
\hline Asian & $7(2)$ & 84.166 \\
\hline Indian/other & $6(1)$ & 97.166 \\
\hline \multicolumn{3}{|l|}{ Work Status } \\
\hline Full Time & $368(79)$ & 84.117 \\
\hline Part Time & $39(9)$ & 78.184 \\
\hline PRN & $30(7)$ & 87.900 \\
\hline \multicolumn{3}{|c|}{ Highest Level of Education } \\
\hline Associates Degree & $195(42)$ & 81.107 \\
\hline Bachelor's Degree & $216(47)$ & 84.392 \\
\hline Master's Degree & $19(5)$ & 92.614 \\
\hline Doctoral Degree & $7(2)$ & 82.857 \\
\hline \multicolumn{3}{|l|}{ Years in Nursing } \\
\hline $0-5$ years & $164(36)$ & 84.190 \\
\hline $6-10$ years & $72(16)$ & 82.333 \\
\hline $11-15$ years & $45(10)$ & 82.933 \\
\hline $16-20$ years & $59(13)$ & 82.796 \\
\hline 21 or more years & $100(21)$ & 84.767 \\
\hline
\end{tabular}

Int J Nurs Clin Pract

ISSN: 2394-4978

IJNCP, an open access journal Volume 2. 2015. 157 


\section{Study Questions Results}

Question 1 asked: "What are the top stressors commonly reported in the working environment of nurses?" The highest three stress scores were work intensely (3.70), have to work fast (3.65), and having a choice in decisions at work (3.20). See Appendix B. The second and third questions were: "What nursing environments are perceived to be the most stressful",and "What type of stressors are most common in those unit specific environments"? Emergency room and medical-surgical floor nurses reported highest stress compared to all departments $(\mathrm{p}<.001)$; no other reported specific stressors were statistically significant (Table 2 ). The fourth and fifths questions were: "What type of nurse reports the most stress", and "Do years of nursing experience or educational level affect the number of reported stressors"? MSN prepared RNs (3.83) reported the highest stress, followed by BSN nurses (3.68) and ASN nurses (3.60). The top two stressors were working fast and intensely. The third highest reported stressor for both the ASN (3.29)and BSN (3.23) nurses was "having a choice in decisions I make at work." The MSN (3.27) prepared RN reported the third highest stressor as, "not being able to take sufficient breaks at work." Years of nursing experience affected nurses' stress perceptions with 0-5 years of nursing experience and nurses with 16 or more years of nursing experience reporting highest stress.

\begin{tabular}{|c|c|c|c|c|c|c|c|c|c|}
\hline \# & Question & ICU & ER & OR & Med-Surgical & Other & Cardiology & $\begin{array}{l}\text { L\&D or } \\
\text { Mother/ } \\
\text { Baby }\end{array}$ & $\begin{array}{l}\text { Mean for all } \\
\text { participants }\end{array}$ \\
\hline 1 & Expectations & 1.48 & 1.58 & 1.61 & 1.52 & 1.54 & 1.50 & 1.58 & 1.54 \\
\hline 2 & Decide about Break Time & 2.31 & 2.80 & 2.85 & 2.47 & 2.57 & 2.25 & 2.54 & 2.57 \\
\hline 3 & Different groups demand too much & 2.78 & 3.04 & 2.50 & 3.12 & 2.77 & 2.63 & 2.83 & 2.88 \\
\hline 4 & Know how to do my job & 1.63 & 1.51 & 1.50 & 1.72 & 1.49 & 1.50 & 1.42 & 1.57 \\
\hline 5 & Personal harassment of unkind words & 1.78 & 2.11 & 1.92 & 2.00 & 1.80 & 1.63 & 1.67 & 1.91 \\
\hline 6 & Unachievable deadlines & 2.09 & 2.29 & 1.93 & 2.50 & 2.10 & 2.00 & 2.25 & 2.21 \\
\hline 7 & Colleagues help me & 1.75 & 1.85 & 1.78 & 1.90 & 1.65 & 2.00 & 1.63 & 1.78 \\
\hline 8 & Given supportive feedback & 2.72 & 2.72 & 2.31 & 2.31 & 2.35 & 2.50 & 2.88 & 2.50 \\
\hline 9 & Work intensively & 3.71 & 4.15 & 3.37 & 3.90 & 3.45 & 3.50 & 3.60 & $3.70^{*}$ \\
\hline 10 & Work speed & 2.48 & 2.96 & 3.08 & 2.55 & 2.75 & 2.50 & 2.48 & 2.71 \\
\hline 11 & Clear of responsibilities & 1.72 & 1.68 & 1.58 & 1.71 & 1.63 & 2.00 & 1.71 & 1.68 \\
\hline 12 & Neglect task because of too much to do & 2.49 & 2.87 & 2.20 & 3.0 & 2.44 & 2.90 & 2.67 & 2.70 \\
\hline 13 & Clear about goals of department & 1.75 & 1.92 & 1.63 & 1.80 & 1.70 & 1.90 & 2.0 & 1.8 \\
\hline 14 & Friction between workers & 2.49 & 2.67 & 2.73 & 2.55 & 2.24 & 2.25 & 2.70 & 2.52 \\
\hline 15 & Choices & 2.32 & 2.51 & 2.63 & 2.34 & 2.44 & 2.25 & 2.50 & 2.42 \\
\hline 16 & Unable to take break & 2.78 & 3.31 & 2.73 & 3.22 & 3.22 & 2.62 & 2.83 & 2.95 \\
\hline 17 & Understand how work fits organization & 1.97 & 2.15 & 1.68 & 1.95 & 1.85 & 2.00 & 1.96 & 1.93 \\
\hline 18 & Pressure to work late & 2.37 & 2.63 & 2.36 & 2.62 & 2.34 & 2.89 & 2.54 & 2.49 \\
\hline 19 & Choice in decisions & 3.23 & 3.45 & 3.22 & 3.13 & 3.13 & 2.63 & 3.17 & 3.20 \\
\hline 20 & Have to work fast & 3.43 & 4.14 & 3.67 & 3.71 & 3.46 & 3.40 & 3.38 & $3.65^{\star}$ \\
\hline 21 & Bullying at work & 1.48 & 1.58 & 1.34 & 1.54 & 1.46 & 1.50 & 1.33 & 1.49 \\
\hline 22 & Unrealistic time pressures & 2.31 & 3.00 & 2.33 & 2.84 & 2.42 & 2.13 & 2.53 & 2.61 \\
\hline 23 & Rely on manager for help & 2.28 & 2.30 & 1.79 & 2.09 & 2.30 & 1.88 & 2.60 & 2.18 \\
\hline 24 & Help and support & 1.84 & 1.86 & 1.78 & 1.90 & 1.72 & 1.90 & 1.92 & 1.82 \\
\hline 25 & Say over how I work & 2.30 & 2.34 & 2.19 & 2.27 & 2.22 & 2.13 & 2.30 & 2.27 \\
\hline 26 & Questions about changes & 2.34 & 2.53 & 2.26 & 2.45 & 2.33 & 1.88 & 2.29 & 2.38 \\
\hline 27 & Respect & 2.23 & 2.21 & 2.16 & 2.21 & 2.10 & 2.50 & 2.29 & 2.38 \\
\hline 28 & Consulted about change & 2.97 & 3.17 & 3.10 & 2.98 & 2.95 & 2.63 & 3.13 & 3.02 \\
\hline 29 & Talk to manager & 2.29 & 2.17 & 2.02 & 2.21 & 2.25 & 2.13 & 2.50 & 2.22 \\
\hline 30 & Working time is flexible & 2.66 & 2.71 & 2.67 & 2.75 & 2.57 & 2.13 & 2.50 & 2.66 \\
\hline 31 & Willing to listen & 2.05 & 2.04 & 2.05 & 2.02 & 2.04 & 2.00 & 2.09 & 2.04 \\
\hline 32 & Changes affect practice & 2.68 & 2.95 & 2.60 & 2.76 & 2.58 & 2.25 & 3.00 & 2.72 \\
\hline 33 & Emotionally supported & 2.40 & 2.61 & 2.36 & 2.50 & 2.30 & 2.50 & 2.35 & 2.43 \\
\hline 34 & Relationships are strained & 2.60 & 2.65 & 2.71 & 2.50 & 2.50 & 2.40 & 2.92 & 2.56 \\
\hline 35 & Manager encourages me & 2.60 & 2.49 & 2.08 & 2.28 & 2.30 & 2.00 & 2.50 & 2.35 \\
\hline
\end{tabular}

Table 2: Unit specific stress and mean for each individual question. 


\section{Discussion}

Nurses have numerous demands relating to work-place stressors regardless of identified unit. This study's results support previous studies conducted using the same instrument. When stressors are experienced by nurses, the ability to provide quality health care is diminished. It is interesting to note that while long careered nurses have knowledge to share with the novice nurse, both reported the highest overall stress. The BSN and MSN prepared nurses perceived more stressors compared to Associate or Diploma prepared RNs. It is believed that nurses with higher educational degrees have a higher knowledge base, are able to view the environment in a broader paradigm, havehigher perceptions of professionalism and maturity compared to less educated nurses, have managerial or charge nurse roles, and that ASN nurses are trained to focus on tasks rather than a holistic view of patient care.

\section{Limitations of the Study}

The study was successful in finding the most common stressors and the variants among nursing units, degree levels, and years of experience; however, a convenience sample conducted at rural hospitals limits the generalizability to larger, urban hospital settings. Nurses were encouraged to complete the survey while on duty possibly influencing responses. Another limitation is that the HSE questionnaire was designed for factory type workers and has not been assessed within healthcare settings to identify nurse working environment stressors.

\section{Conclusion}

Multiple healthcare organizations were used in this study; however further studies conducted in multifaceted nursing environments are needed. The results of this study demonstrate that RNs experiencemany stressors that affect quality and safe patient care and adds to the literature that nurses in fast paced areas such as the emergency room and medical-surgical units have increased stressors compared to other hospital units; MSN prepared nurses reported higher stress rates than any other degree. Interesting to note is that nurses reporting the highest stress are nurses with more than 21 years of experience, new nurses (0-5 years), and those with higher education degrees. Nurse Manager's mustimprove the psychosocial environment and reduce demands and stressors experienced byRNs. Also, nurse educators must better prepare student nurses for today's ever changing healthcare settings and stressors they may encounter.

\section{Implications for Nursing Practice}

Nurses are pivotal in providing health care; however, work-related stressors affect that care. The forecasted shortage may result in even higher physical and mental health nurse risks and vulnerabilities. Transformational leadership decrease exhaustion and increases well-being, job satisfaction, and better job outcomes of nurses[26]. Therefore, healthcare systems must train thesenurse leaders toidentify criticalRN stressors, increase flexibility, stimulate positive ideas within nursing systems, and develop strategies that increasehealthy work environments, job satisfaction,nurse resilience and retention thus reducing staff turnover rates. Implementing targeted, constructive workplace policies that address stressors experienced by nurses affects the organization and the entire nursing profession. Nurses desire a positive, healthy environment where they feel valued through positive policy and procedure changes when necessary.

\section{Dissemination}

After analysis, the researcher discussed the findings with the participating agencies in order to assist in determining effective strategies to alleviate or reduce the most common stressors identified in their facilities. Small adjustments and specific stressor protocols development could result in improved satisfaction within each organization and larger changes at the state or even national level. Other venues include oral and/or written presentations at local, regional and national conferences.

\section{Competing Interests}

The authors have no competing interests with the work presented in this manuscript.

\section{References}

1. Tsai YC, Liu CH (2012) Factors and symptoms associated with work stress and health-promoting lifestyles among hospital staff: a pilot study in Taiwan. BMC Health Serv Res 12: 199.

2. Witkoski A, Dickson VV (2010) Hospital staff nurses' work hours, meal periods, and rest breaks. A review from an occupational health nurse perspective. AAOHN J 58: 489-497.

3. Kaufman G, McCaughan D (2013) The effect of organisational culture on patient safety. Nurs Stand 27: 50-56.

4. Perry B (2008) Shine on: achieving career satisfaction as a registered nurse. J Contin Educ Nurs 39: 17-25.

5. Budin WC, Brewer CS, Chao YY, Kovner C (2013) Verbal abuse from nurse colleagues and work environment of early career registered nurses. J Nursing Scholarsh 45: 308-316.

6. Bambi S, Becattini G, Giusti GD, Mezzetti A Guazzini A et al (2014) Lateral hostilities among nurses employed in intensive care units, emergency departments, operating rooms, and emergency medical services. A national survey in Italy. Dimens Crit Care Nurs 33: 347-354.

7. Watson R, Gardiner E, Hogston R, Gibson H, Stimpson A, et al. (2009) A longitudinal study of stress and psychological distress in nurses and nursing students. J Clin Nurs 18: 270-278.

8. Khamisa N, Oldenburg B, Peltzer K, llic D (2015) Work related stress, burnout, job satisfaction and general health of nurses. Int J Environ Res Public Health 12: 652-666.

9. IOM Report: Nurses Hold Key To Patient Safety 66: 12.

10. Geiger-Brown J, Rogers VE, Trinkoff AM, Kane RL, Bausell RB, et al. (2012) Sleep, sleepiness, fatigue, and performance of 12-hour-shift nurses. Chronobiol Int 29: 211-219.

11. Geiger-Brown J, Trinkoff A, Rogers VE (2011) The impact of work schedules, home, and work demands on self-reported sleep in registered nurses. J Occup Environ Med 53: 303-307.

12. Geiger-Brown J, Trinkoff AM (2010) Is it time to pull the plug on 12-hour shifts?: Part 1. The evidence. J Nurs Adm 40: 100-102.

13. Han K, Trinkoff AM, Geiger-Brown J (2014) Factors associated with workrelated fatigue and recovery in hospital nurses working 12-hour shifts. Workplace Health Saf 62: 409-414.

14. Trinkoff AM, Le R, Geiger-Brown J, Lipscomb J () Work schedule, needle use, and need lestick injuries among registered nurses. Infect control hosp Epidemiol 28: 156-164.

15. Trinkoff AM, Lipscomb JA, Geiger-Brown J, Brady B (2002) Musculoskeletal problems of the neck, shoulder, and back and functional consequences in nurses. Am J Ind Med 41: 170-178.

16. Venkatesh A, Goodrich K, Conway PH (2014) Opportunities for quality measurement to improve the value of care for patients with multiple chronic conditions. Ann Intern Med 161: S76-80.

17. Hackbarth AD, Munier WB, Eldridge N, Jordan J, Richards C, et al. (2014) An overview of measurement activities in the partnership for patients. J Patient Saf 10: 125-132. 
18. Gu Q, Koenig L, Faerberg J, Steinberg CR, Vaz C, et al. (2014) The Medicare Hospital Readmissions Reduction Program: potential unintended consequences for hospitals serving vulnerable populations. Health Serv Res 49: 818-837.

19. Duffield C, Diers D, O'Brien-Pallas L, Aisbett C, Roche M, et al. (2011) Nursing staffing, nursing workload, the work environment and patient outcomes. Appl Nurs Res 24: 244-255.

20. Aiken LH, Clarke SP, Sloane DM, Lake ET, Cheney T (2008) Effects of hospital care environment on patient mortality and nurse outcomes. J Nurs Adm 38: 223-229.

21. Cimiotti JP, Aiken LH, Sloane DM, Wu ES (2012) Nurse staffing, burnout, and health care-associated infection. Am J Infect Control 40: 486-490.

22. Doody O, Doody CM (2012) Transformational leadership in nursing practice. Br J Nurs 21: 1212-1214, 1217-8.

23. Happell B, Dwyer T, Reid-Searl K, Burke KJ, Caperchione CM, et al. (2013) Nurses and stress: recognizing causes and seeking solutions. J Nurs Manag 21: 638-647.

24. Suc J, Prokosch HU, Ganslandt T (2009) Applicability of Lewin s change management model in a hospital setting. Methods Inf Med 48: 419-428.

25. Kerr R, McHugh M, McCrory M (2009) HSE management standards and stress-related work outcomes. Occup Med (Lond) 59: 574-579.

26. Weberg D (2010) Transformational leadership and staff retention: an evidence review with implications for healthcare systems. Nursing administration quarterly $34: 246-258$. 